Published in final edited form as:

Ann Behav Med. 2016 June ; 50(3): 385-396. doi:10.1007/s12160-015-9765-5.

\title{
I Keep my Problems to Myself: Negative Social Network Orientation, Social Resources, and Health-Related Quality of Life in Cancer Survivors
}

\author{
Christine Rini, $\mathrm{PhD}^{1,2}$, Yael Symes, MSPH${ }^{1,2}$, Rebecca A. Campo, $\mathrm{PhD}^{3}$, Lisa M. Wu, $\mathrm{PhD}^{4,5}$, \\ and Jane Austin, $\mathrm{PhD}^{6}$ \\ Christine Rini: christine.rini@unc.edu \\ ${ }^{1}$ Gillings School of Global Public Health, Department of Health Behavior, University of North \\ Carolina at Chapel Hill, Campus box 7440, 319C Rosenau Hall, Chapel Hill, NC 27599-7440, \\ USA \\ ${ }^{2}$ UNC Lineberger Comprehensive Cancer Center, Chapel Hill, NC, USA \\ ${ }^{3}$ Department of Physical Medicine and Rehabilitation, University of North Carolina at Chapel Hill, \\ Chapel Hill, NC, USA \\ ${ }^{4}$ Department of Medical Social Sciences, Feinberg School of Medicine, Northwestern University, \\ Chicago, IL, USA \\ ${ }^{5}$ Robert H. Lurie Comprehensive Cancer Center, Chicago, IL, USA \\ ${ }^{6}$ Department of Psychology, William Paterson University, Wayne, NJ, USA
}

\begin{abstract}
Background-Cancer survivors treated with hematopoietic stem cell transplant rely on their social network for successful recovery. However, some survivors have negative attitudes about using social resources (negative social network orientation) that are critical for their recovery.
\end{abstract}

Purpose-We examined the association between survivors' social network orientation and health-related quality of life (HRQoL) and whether it was mediated by social resources (network size, perceived support, and negative and positive support-related social exchanges).

Methods-In a longitudinal study, 255 survivors completed validated measures of social network orientation, HRQoL, and social resources. Hypotheses were tested using path analysis.

Results-More negative social network orientation predicted worse HRQoL $(p<.001)$. This association was partially mediated by lower perceived support and more negative social exchanges.

Correspondence to: Christine Rini, christine.rini@unc.edu.

Authors' Contributions All authors contributed significantly to the manuscript and have seen and approved it.

Authors' Statement of Conflict of Interest and Adherence to Ethical Standards Christine Rini, PhD, Yael Symes, MSPH, Rebecca A. Campo, PhD, Jane Austin, $\mathrm{PhD}$, Lisa M. Wu, PhD declare that they have no conflict of interest. All procedures, including the informed consent process, were conducted in accordance with the ethical standards of the responsible committee on human experimentation (institutional and national) and with the Helsinki Declaration of 1975, as revised in 2000. 
Conclusions-Survivors with negative social network orientation may have poorer HRQoL in part due to deficits in several key social resources. Findings highlight a subgroup at risk for poor transplant outcomes and can guide intervention development.

\section{Keywords}

Cancer survivors; Network orientation; Social support; Health-related quality of life; Hematopoietic stem cell transplantation

Hematopoietic stem cell transplant is an increasingly common treatment for hematologic cancers and other diseases. Although often life-saving, it is medically risky and causes substantial physical and psychosocial burden. Specifically, transplant typically begins with a toxic preparative regimen of high-dose chemotherapy and, for some, total body irradiation. Even patients receiving less toxic regimens have substantial physical and psychological symptoms (e.g., due to immunosuppression, reduced but still significant toxicity, and the fact that these patients are often older or sicker at the time of transplant) [1]. Transplant recipients face a prolonged treatment and recovery period characterized by lengthy hospital stays with aversive procedures; potentially life-threatening side effects and complications; ongoing risk of relapse and late effects; difficulties with work, financial, and family roles; social isolation; and complex self-care [2, 3]. Consequently, during this time, they are highly dependent on social resources such as social support from family, friends, and others in their social network. These informal caregivers provide survivors with companionship and emotional support, assist with daily tasks and responsibilities, and help with ongoing medical care [2]. Indeed, this support is so critical that one key goal of pre-transplant screening is to ensure the presence of reliable informal caregivers $[4,5]$.

A recent review revealed reliable evidence for the association between greater social support and better post-transplant outcomes, including better health-related quality of life (HRQoL) [6] - a key patient-reported outcome. For instance, one study of cancer patients undergoing autologous or allogeneic transplant (i.e., a transplant using the recipient's or a donor's stem cells, respectively) found that having more stable pre-transplant support and care giving was associated with improved survival rates and better post-transplant HRQoL [7]. Another study found that having greater perceived support prior to allogeneic transplant was associated with having lower depressive symptoms 1 year post-transplant [8]. Similarly, a longitudinal study of both autologous and allogeneic transplant recipients found that higher pre-transplant satisfaction with social support predicted better post-transplant psychological functioning, including lower depressive symptoms and faster recovery from transplantrelated distress [9]. Thus, a variety of indicators of social resources are associated with better HRQoL among cancer survivors treated with stem cell transplant.

The present study examined a phenomenon that has received little research attention despite the importance placed on social resources in clinical practice and evidence supporting their importance for survivors' HRQoL. Not all survivors hold positive beliefs and expectations about drawing upon their potentially available social resources. Furthermore, survivors who hold negative beliefs and expectations (i.e., they have a "negative social network orientation" $[10,11])$ may be less likely to draw on these resources in times of need, and they may have 
fewer and lower quality social resources available to them when they have no choice but to rely on them. To the extent these problems occur, theory and research suggest that having a more negative social network orientation will negatively affect survivors' HRQoL. Little is currently known about these processes, in part because it is generally assumed that people treated for cancer, including those undergoing transplant, welcome and accept as much support as possible. If negative social network orientation is associated with poor HRQoL, it would be useful to understand which social resources are most strongly implicated in this association to guide further research as well as the development of interventions to address or accommodate these problems.

\section{Social Resources}

The term "social resources" encompasses a range of concepts, including the size of a person's social network (network size), perceptions about support available if needed (perceived support), and reports of positive and negative social exchanges related to social support (conceptually related to the effectiveness of enacted support) [12-16]. Benefits of having a larger social network have not been studied in transplant recipients, but in other cancer populations, evidence links having a larger network with better health outcomes such as reduced mortality risk [17] and better HRQoL [18]. For instance, a study of lymphoma survivors found that those who reported having more close friends and family members had better general and cancer-specific HRQoL [19]. These kinds of associations may be traced to mechanisms such as better access to health care or other health-promoting resources, as well as beneficial social regulation of health behaviors (e.g., expressed disapproval of negative health behaviors) $[17,20,21]$.

Knowing the size of a person's social network does not provide information about the support available or exchanged within the network; however, this information is provided by measures of perceived social support and positive and negative social support-related social exchanges (hereafter referred to as "social exchanges" for brevity). Perceived support and positive social exchanges may buffer adverse effects of stressors [12, 20, 22] or promote more effective coping [23], leading to better physical and psychological functioning-key aspects of HRQoL. For instance, these positive social resources provide perceived or real access to informational support (e.g., information about ways to cope with a stressor or advice on how to follow self-care recommendations), instrumental assistance (e.g., assistance with finances or practical needs, such as getting to medical appointments), and emotional support (e.g., listening to concerns and demonstrating caring) [22]. In contrast, negative social exchanges (e.g., unwanted advice, unhelpful assistance, or insensitive emotional support attempts) may fail to provide coping assistance or to mitigate adverse effects of stressors, reducing HRQoL [24, 25]. Evidence supports the importance of differentiating between positive and negative social exchanges. For instance, in a study of transplant survivors, Rini and colleagues [26] found that social support received from a spouse or partner was associated with better psychological well-being - a domain of HRQoL —but only if it was effective (i.e., sensitively provided, with a good match between the quantity and quality of support provided and the recipient's needs) [27]. 
These structural and functional social resources are empirically and conceptually distinct $[28,29]$. For instance, perceptions of available support do not necessarily reflect actual support exchanged during times of adversity [30,31], and people with large social networks may only rely on a few people within their network for day-to-day support. Yet, to the extent that having a larger social network may promote better HRQoL by increasing access to functional social resources, then perceived support and positive and negative social exchanges could be viewed as more proximal predictors of HRQoL and potentially have larger associations with this outcome than would network size. At the same time, network size could influence HRQoL in ways that are not well assessed by measures of perceived support and social exchanges. For instance, network members' social control efforts aimed at increasing survivors' positive health behaviors, and survivors' perceived responsibilities to get healthy for network members, may help motivate survivors to adherence to recommended medications and self-care activities, and group memberships can provide a psychologically beneficial sense of identity and meaning in life [32, 33]. Thus, each of these social resources has the potential to benefit survivors' HRQoL.

\section{Social Network Orientation}

One gap in research on social resources and survivors' HRQoL is that it has not considered the possibility that some people are not comfortable tapping into their social resources, even when those resources could help them manage the challenges and stressors they face during and after treatment. They hold expectations and beliefs that accessing support is unpleasant, unhelpful, unwise, or risky, and they experience getting support in these ways. This concept was first described by Tolsdorf [10] who studied male veterans hospitalized for psychiatric or medical problems and their views about how their social network could help them cope with stressors. Some veterans reported that it was safe, advisable, and sometimes necessary to get support from their network (a positive social network orientation), whereas others reported that it was impossible, inadvisable, useless, or possibly dangerous to do so (a negative social network orientation). Veterans with a negative social network orientation did not use support from their network and intended not to do so in the future. Moreover, they received unhelpful support (e.g., because they revealed little information to guide support provision). The majority of veterans with a negative social network orientation appeared to have had this orientation since childhood; this weakened their adult relationships in later life in addition to affecting their behaviors toward network members.

Since Tolsdorf's study, Vaux and colleagues [11,34] developed and validated a measure of social network orientation to facilitate research, and other researchers have studied conceptually related constructs such as help-seeking beliefs, efficacy of help seeking, support seeking behaviors, help-seeking comfort, and active social orientation [35-38]. This research has revealed findings similar to Tolsdorf's in healthy populations and in both genders [11, 34, 39], and it indicates that social network orientation is a relatively stable, dispositional characteristic [11]. Research has also found that, compared to people with a more positive social network orientation, those with a more negative social network orientation have smaller networks, fewer reciprocal relationships, and less perceived and received social support $[11,35,36]$. In addition, they are less likely to seek and use support resources $[11,35]$ or to appraise support in positive terms (e.g., they feel less cared for) [11]. 
In sum, although it is commonly assumed that people recovering from a difficult cancer treatment, such as stem cell transplant, will mobilize or accept all the support available to them, and that they will welcome and benefit from it, research on negative social network orientation suggests that some are less likely to perceive, seek, use, and benefit from support from others. These characteristics could translate to survivors with a more negative social network orientation having worse HRQoL than those with a more positive orientation. Understanding the effects of negative social network orientation could help identify opportunities for interventions in survivors who are at risk for poor outcomes because of their inability to benefit from critical social resources.

\section{Summary of the Present Study}

In the present study, we examined associations between negative social network orientation and HRQoL (both concurrent and prospective, assessed 4 months later) among 255 cancer survivors treated with stem cell transplant, then investigated whether that association could be at least in part explained through variation in four social resources: social network size, perceived social support, and positive and negative social exchanges. Based on the evidence described above, we hypothesized that transplant survivors with a more negative social network orientation would report worse HRQoL concurrently and prospectively and that this association would be at least partially mediated by their smaller social network of potential support providers, lower perceived social support, more frequent negative social exchanges (e.g., ineffective enacted support), and less frequent positive social exchanges (e.g., effective enacted support).

\section{Methods}

Participants

Participants were 255 men and women who completed a randomized control trial testing a psychosocial writing intervention for stem cell transplant survivors [40]. To be eligible for the trial, they had to have had a successful stem cell transplant 9 months to 3 years prior to the study, speak English, be at least 18 years old, and have access to a telephone (because study procedures were completed by telephone). Additionally, they had to have at least mild survivorship problems in one or more of the following domains: general distress (Brief Symptom Inventory [41]); cancer-specific distress (Impact of Event Scale [42]); HRQoL (Functional Assessment of Cancer Therapy-Bone Marrow Transplant [43, 44]); and purpose in life (Life Engagement Test [45]). Exclusion criteria for the trial included substance abuse disorder, active psychosis, active suicidal ideation, or significant cognitive impairment. Of the 437 potential participants screened, 369 (84\%) were eligible; 315 of those survivors were randomized ( $85 \%)$ and 264 of the randomized survivors completed the follow-up assessment (84\%) about 1 week post-intervention. Attrition was primarily due to loss of contact $(55 \%)$ or relapse/death (33\%). Participants were excluded from analyses for the present study if they had not completed the follow-up assessment $(n=51)$ or they were missing social network orientation or social resource data (an additional $n=9$ ). Compared to the sample of 255 participants in the present study, the 60 who were excluded were younger ( $M=54.45$ years versus $M=50.5$ years, respectively; $p=.02$ ) and marginally less likely to 
be non-Hispanic white ( $86 \%$ versus $77 \%$, respectively; $p=.08$ ). The two groups did not differ on baseline or follow-up HRQOL or any of the social resource variables. In addition, examination of screening data indicated that survivors who were eligible for randomization but not randomized did not differ from those included in the present study on gender, age, race/ethnicity (non-Hispanic white vs. other), type of transplant (allogeneic vs. autologous), or HRQOL at screening.

\section{Procedure}

Participants were recruited between 2008 and 2011 through advertisements and patient databases at Mount Sinai Hospital (New York, NY) and Hackensack University Medical Center (Hackensack, NJ). Telephone screening interviews were conducted to establish participants' eligibility. Eligible participants completed informed consent procedures by phone. Next, they completed a baseline assessment that included a mailed questionnaire and phone interview, which took approximately $45 \mathrm{~min}$ and was conducted by a trained staff member. Participants were then randomly assigned and began the parent study's intervention. Details of the parent study's procedures and recruitment are provided in a report of that study [40]. The Institutional Review Boards at the study sites approved the procedures.

\section{Measures}

Health-Related Quality of Life-HRQoL was assessed with the 37-item Functional Assessment of Cancer Therapy-Bone Marrow Transplant scale (FACT-BMT [43, 44]). This instrument measures four quality-of-life domains including physical (e.g., "I am bothered by side effects of treatment"), functional (e.g., "I am able to work"), social and family (e.g., "My illness is a personal hardship for my close family members"), and emotional well-being (e.g., "I worry about dying") in addition to transplant-specific concerns (e.g., "The effects of treatment are worse than I had imagined"). Responses about experiences in the prior 7 days were provided on a scale from 0 (not at all) to 4 (very much). Negatively worded items were reversed scored and responses were summed so that higher scores indicated better HRQoL (Cronbach's $a=.90$ ). Possible scores range from 0 to 148 . Two of the 37 FACT-BMT items were conceptually similar to social exchange items ("I get emotional support from my family" and "I get support from my friends"). Excluding them did not alter the results or the study's conclusions. Because that was the case, and because this is a validated scale, all findings are reported with these items included.

Social Network Orientation-Social network orientation was assessed with the Network Orientation Scale (NOS) [11], which measures negative expectations, attitudes, and beliefs about the desirability and effectiveness of seeking or receiving support from one's network. It has been shown to be reliable and valid in various populations (e.g., 11, 39, and 46). We used an 18-item version, based on a factor analysis [34]. Participants rated their agreement with items such as "Sometimes it's necessary to talk to someone about your problems" [reverse scored], "If you confide in other people, they will take advantage of you," and "If you can't figure out your problems, nobody can" on a scale from 1 (strongly disagree) to 4 (strongly agree). Items were reverse scored as necessary and summed to form a scale with 
possible scores of 18 to 72 , with higher scores indicating a more negative social network orientation (i.e., lower likelihood of using social network resources; Cronbach's $a=.82$ ).

Social Network Size-The social network size was assessed with Cohen's Social Network Index [13], which measures the number of people with whom respondents have regular contact (i.e., at least once every 2 weeks) across 12 types of relationships, including their relationships with a spouse/partner, parents, parents-in-law, children, other close family members, close neighbors, friends, coworkers, fellow students or teachers, fellow volunteers, and members of groups with and without a religious affiliation. Possible scores range from 0 to 168 , with higher scores indicating a larger, more diverse network.

Perceived Social Support-Perceived social support was measured with the 7-item ENRICHD Social Support Inventory [15]. One item assesses whether respondents are married or partnered (scored 4 for "yes" and 2 for "no"). An additional six items assess perceived availability of emotional, instrumental, and informational support on a scale from 1 (none of the time) to 5 (all of the time).Responses are summed so that possible scores range from 8 to 34 , with higher scores indicating greater perceived support $(\alpha=.82)$.

Positive and Negative Support-Related Social Exchanges-Positive and negative support-related social exchanges were assessed with the 24-item Positive and Negative Social Exchanges Scale [16]. It measures four types of positive social exchanges (informational support, instrumental support, emotional support, companionship) and four types of negative social exchanges (unwanted advice or intrusion, failure to provide help, unsympathetic or insensitive behavior, rejection or neglect) in the past month on a scale from 1 (never) to 5 (very often). Separate responses are provided for a partner (if applicable) and other people; for participants with partners, these scores were averaged. Responses for positive and negative social exchanges were summed separately to produce separate scores for these two domains. Possible scores ranged from 12 to 60, with higher scores indicating more frequent positive $(\alpha=.90)$ and negative social exchanges $(\alpha=.89)$.

Sociodemographic Characteristics-Sociodemographic characteristics were selfreported and included age, ethnicity, gender, marital/partner status, current employment status, and years of education.

Medical Information-Medical information was obtained via medical chart review and self-report. Type of transplant was either autologous (using a patient's own stem cells) or allogeneic (using stem cells from a donor) [46]. Participants were asked whether they had these eight complications or side effects after their transplant: infection, pneumonia, low platelets or low red blood cells, bleeding, veno-occlusive disease (liver damage), lung or heart complications, mucositis (mouth sores), or engraftment problems after transplant. Endorsed items were summed to create a scale ranging from 0 to 8 . History of graft versus host disease (GvHD; either acute or chronic), which occurs when donor cells recognize a patient's tissue as foreign and attack them, was modeled separately (no $=0$, yes $=1$ ) because it is associated nearly exclusively with allogeneic transplant. Medical comorbidities were assessed with the Self-Administered Comorbidity Questionnaire [47]. Comorbidities 
endorsed by participants (e.g., heart disease, high blood pressure, diabetes) were summed to create a scale with a possible range from 0 to 45 .

\section{Analytic Strategy}

Data were screened for violations of analytic assumptions. Next, we computed descriptive statistics and bivariate correlations to identify sociodemographic and medical covariates that were significantly associated with HRQoL. We then tested hypotheses using path analysis, implemented in EQS 6.2 with maximum likelihood estimation [48]. The hypothesized model is shown in Fig. 1. It controlled for the randomly assigned writing intervention groups (three dummy-coded variables) and sociodemographic and medical covariates that were significantly associated with follow-up HRQoL in bivariate analyses. Model fit was evaluated with multiple indicators, including $\chi^{2}$ (good fit is indicated by non-significance), the comparative fit index (CFI) (good fit is indicated by values over .95), the root-meansquare error of approximation (RMSEA) (good fit is indicated by a value of $\leq 05$ and reasonable fit is indicated by values between .05 and .08) [49], and the standardized room mean-square residual (SRMR) (good fit is indicated by values <.10) [50]. Modification indices (Wald and Lagrange multiplier tests) were consulted for suggested model modifications.

\section{Results}

Participant characteristics appear in Table 1. Most were non-Hispanic white, had a spouse or partner, had completed a 4-year college degree or more education, and had a relatively high median household income, although broad ranges of education levels and household income suggested variability in socioeconomic status. Over half of the participants were women and most had an autologous transplant (i.e., they received an infusion of their own stem cells rather than stem cells from a donor, which occurs in allogeneic transplant). The most common diagnoses were lymphoma (Hodgkin lymphoma, non-Hodgkin lymphoma), multiple myeloma, and leukemia (chronic or acute). Participants had undergone stem cell transplant an average of 20 months prior to the study ( $S D=8.05$; range 8 to 46 months).

Social network orientation scores ranged from 21 to 52 and were normally distributed. At the low end, the scores corresponded to strong disagreement with all statements indicating negative social network orientation (i.e., a response of just over "1" to each one); at the high end, they corresponded to moderate agreement with those statements (i.e., responses averaging just below 3 to each statement). Thus, no participants reported a high negative social network orientation, similar to studies in non-cancer samples (e.g., [51, 52]). Average HRQoL at both assessments was comparable to the HRQoL reported by McQuellon and colleagues [43] for their sample of patients scheduled for stem cell transplant, and HRQoL was relatively stable over the 4-month study period, as indicated by the high correlation of $r=.79$.

Bivariate correlations between study variables appear in Table 2. Negative social network orientation was modestly correlated in expected directions with the social resource variables and HRQoL at both assessments. Intercorrelations among the social resource variables were small to moderate, supporting the fact that these resources are empirically distinct. They 
were also correlated with HRQoL at both assessments. Demographic and medical variables associated with HRQoL at follow-up included household income $(r=.16, \mathrm{p}=.016)$, number of medical comorbidities $(r=-.41, p<.001)$, number of transplant complications $(r=-.32$, $p<.001)$, and history of GvHD ( $1=$ yes, $0=$ no $)(t(253)=-3.63, p<.000)$. Consequently, these variables were included as covariates in the structural equation model; their association with follow-up HRQoL was assumed to operate through baseline HRQoL. Transplant type $(1=$ autologous, $0=$ allogeneic $)$ was also associated with HRQoL at follow-up $(t(253)=$ $-2.75, p=.006$ ). It was not included as a covariate because it is strongly confounded with the history of GvHD (which is relatively common after allogeneic transplant but rarer after autologous transplant). Due to its serious effects on HRQoL [53], GvHD was considered a more critical covariate than type of transplant.

\section{Test of the Hypothesized Model}

The $\chi^{2}$ test for the hypothesized model indicated room for improvement in terms of the model fit: $\chi^{2}(61)=226.02, p<.001, \mathrm{CFI}=.80$, SRMR $=.10, \mathrm{RMSEA}=.10(90 \%$ confidence interval (CI) 0.09-0.12). Modification indices suggested several substantive and conceptually defensible changes, including the following: (1) dropping direct paths from positive social exchanges and social network size to baseline HRQoL; (2) dropping direct paths from social network orientation and all four social resource variables to follow-up HRQoL (leaving only indirect effects of negative social exchanges and perceived support on follow-up HRQOL, through baseline HRQoL, to be estimated); (3) dropping income and writing conditions as covariates; and (4) allowing the error variance of perceived support to covary with the error variances of positive and negative social exchanges (most likely reflecting their underlying similarities as indicators of functional aspects of social resources, differentiating them from social network size). All of these adjustments were made with the exception of dropping the writing conditions as covariates; they were retained because of their conceptual importance. These changes yielded a more parsimonious model with adequate fit: $\chi^{2}(55)=78.11, p=.02, \mathrm{CFI}=.97, \mathrm{SRMR}=.07, \mathrm{RMSEA}=.04(90 \%$ CI $0.02-$ $0.06)$.

Findings from this final model are shown in Fig. 2, with standardized parameter estimates. They indicate that having a more negative social network orientation was associated with poorer social resources of all four types in the expected directions: lower perceived support ( $z=-5.02, p<.001$ ), smaller social network ( $z=-2.32, p=.02$ ), fewer positive social exchanges $(z=-4.05, p<.001)$, and more negative social exchanges $(Z=3.81, p<.001)$. However, only two of those resources had a direct association with baseline HRQoL: perceived support $(z=5.00, \mathrm{p}<.001)$ and more negative social exchanges $(z=-6.10, \mathrm{p}<.001)$. In addition, there was a direct association between negative social network orientation and baseline HRQoL ( $z=-2.46, p=.01$ ). Baseline HRQoL had a strong direct positive association with follow-up HRQoL ( $z=15.20, p<.001)$, consistent with the strong correlation between HRQoL assessed at these two time points. Neither negative social network orientation nor any of the social resources variables had a direct association with follow-up HRQoL, controlling for other variables in the model including baseline HRQoL. However, there were indirect effects of social network orientation ( $\beta=.23, z=-4.93, p<.001)$, perceived social support $(\beta=.22, z=04.85, p<.001)$, and negative social exchanges $(\beta=-.27, z=-5.83, p<$. 
001) on follow-up HRQoL, all in the expected directions. In addition, worse baseline HRQoL was associated with having a greater number of non-GvHD transplant complications $(z=-3.40, p<.001)$, a history of $\operatorname{GvHD}(z=-3.01, p=.003)$, and a greater number of medical comorbidities $(S=-8.18, p<.001)$.

\section{Discussion}

Many cancer survivors use the social resources available to them and benefit from them in various ways; however, those with negative social network orientation may be limited in the extent to which they have, access, and benefit from these resources. The present study examined this understudied phenomenon among cancer survivors treated with stem cell transplant-a population highly dependent on social resources during their lengthy treatment and recovery. Findings highlight a subgroup at risk for poor transplant outcomes and can guide development of interventions.

The findings also extend knowledge of processes surrounding negative social network orientation. Past research has shown that people with a more negative social network orientation have smaller social networks, more negative social exchanges, less perceived support, and less positive social exchanges [11, 35-39]. An important contribution of this study is that it examined these social resources in a single study, evaluating their ability to mediate the association between negative social network orientation and health-related quality of life, controlling for potential medical confounds. Findings indicated that, compared to survivors with a more positive social network orientation, survivors with a more negative social network orientation were more likely to expect that less support would be available if they needed it, and when they did receive it, they were either more likely to experience it as being negative or it was more likely to actually be negative. These negative expectations and experiences were, in turn, associated with lower functioning in important life domains.

When interpreting these findings, it is important to keep in mind that social network orientation is a relatively stable individual difference thought to originate, at least in part, from people's lifetime experiences with social resources in times of need [10, 11]. Similarly, social support behaviors, appraisals, and expectations are thought to have origins in early life experiences in addition to being influenced by a history of interactions with important social network members [16, 29]. Adult attachment theory addresses processes like these and may provide insight into our findings as well as guidance for extending them. For instance, attachment researchers theorize that children's relationships with their caregivers create beliefs, attitudes, and expectations that endure to affect their behaviors in adult relationships [56], including those related to social support [55, 57]. Consistent evidence was shown by Wallace and Vaux (1993) who found that adults with a secure adult attachment style had a more positive social network orientation than adults with an insecure attachment style, who were more likely to mistrust others and to believe it to be inadvisable to rely on others.

It is also important that the significant paths linking social network orientation, perceived support, and negative social exchanges with health-related quality of life involved concurrent associations at baseline; effects of social network orientation and these social resources on 
follow-up health-related quality of life were fully explained by their associations with baseline health-related quality of life. One potential explanation for this pattern of findings involves the strong association between baseline and follow-up health-related quality of life in these longer-term survivors. Thus, there was relatively little change from baseline to follow-up to predict. It may also be that the lack of prospective effects reflected methodological shortcomings of measuring mediators at the same time as a predictor [58]. However, this approach made conceptual sense in this study given that social network orientation and associated social resources are relatively stable characteristics that patients bring to their treatment and recovery. In addition, the timing of the follow-up may have played a role, in that perceived social support and negative social exchanges were unlikely to change over the brief 4-month study period without a specific intervention designed to change them. This possibility is especially likely given that we studied survivors who were beyond the acute phase of transplant recovery compared to soon after transplant when social resources are more likely to be mobilized. Finally, stem cell transplant is typically not the first line of treatment for hematological malignancies. As such, by the time people undergo transplant, their health-related quality of life will have already been reduced by prior chemotherapy, radiation, steroids, and other treatments. Future studies should begin closer in time to diagnosis, include longer-term follow-up, and measure changes in the potential mediators.

Positive social exchanges and network size did not mediate the association between negative social network orientation and poor health-related quality of life, suggesting that interventions focused on improving these aspects of social resources would be relatively unlikely to yield better outcomes for people with negative social network orientation. Although we posited that network size can influence health-related quality of life in ways that are not well assessed by functional measures of support (e.g., enhancing motivation to adhere to healthy behaviors or providing a sense of identity), it may be that such influences, if they occur, are relatively unimportant in this population or that network size is too inexact an indicator of social resources to be useful here. With respect to the lack of mediation by positive social exchanges, our findings are consistent with research demonstrating that negative social support is more reliably associated with recipient well-being and distress than are more positive social support [16].

It is notable that the association between having a more negative social network orientation and poorer post-transplant health-related quality of life remained significant even after accounting for social resource deficits and medical confounds. Thus, there is a need to investigate other potentially important mechanisms. It may be worthwhile to consider the role of intrapersonal variables such as distress or low self-esteem. During the lengthy posttransplant recovery period, survivors need extensive assistance with daily activities and behaviors necessary for preventing and managing transplant-related complications [5]. Those with a more negative social network orientation may find this situation distressing and inconsistent with valued perceptions of being self-reliant, potentially slowing their physical and emotional recovery by interfering with critical health behaviors or engaging stressrelated pathways [59]. 


\section{Implications for Interventions}

Our findings are consistent with robust research indicating that perceived support and negative social exchanges are strongly associated with health outcomes [16, 59, 60], suggesting that these social resources may be good targets for interventions to improve health-related quality of life in transplant survivors with negative social network orientation. Additional longitudinal research specifically designed to evaluate the causal associations underlying our findings [61] would help ensure that these interventions will be effective. The nature of the social resources that emerged as most important suggests the need to address negative expectations about social support available to survivors or survivors' negative appraisals of social exchanges involving social support. Of the two, negative social exchanges may be more amenable to change (e.g., by adapting cognitive-behavioral approaches teaching people to mobilize and manage social support). Increasing perceived social support is more challenging, although possible; a recent meta-analysis of community public health interventions revealed that these interventions lead to a reliable increase in perceived social support of approximately moderate size [54]. It may also be useful to focus on providing social resources from sources outside survivors' intimate social network-for instance, from support groups or healthcare providers [36]. This approach may help offset reciprocity obligations or interpersonal costs of receiving support and place less psychological strain on the patient, caregivers, and their relationship.

\section{Limitations}

This study had several limitations, including those described above involving the lack of longer-term follow-up. The present study's brief study period (4 months) paired with investigation of variables that were relatively stable over time hindered examination of prospective associations. As noted, we recommend a study of transplant recipients closer in time to their treatment, with longer-term follow-up, and measurement of changes in all study variables, including proposed mediators. In addition, the sample was predominantly nonHispanic white, although the sample's demographics were similar to those found in the larger population of people undergoing stem cell transplant [62].

\section{Contributions}

This study provides early evidence for variation in the social network orientation of a cancer population for which social resources are critical. It demonstrates a potential pathway whereby negative social network orientation predicts worse health-related quality of life among transplant survivors in important life domains-physical, functional, social and family, emotional well-being, and transplant concerns - in part due to low perceived social support and negative social exchanges. These are useful findings considering the lack of attention to the possibility that not all cancer survivors are equally likely to accept and benefit from critical social resources. Moreover, the study examined multiple aspects of social support, finding that some offer a more plausible explanation than others for the association between negative social network orientation and health-related quality of life. These findings therefore suggest avenues for additional research and interventions to improve health-related quality of life in stem cell transplant survivors and related populations. 


\section{Acknowledgments}

This research was supported by the American Cancer Society, grant \#RSGPB-07-285-01-CPPB (PI: Rini). Lisa Wu's effort was supported by the National Cancer Institute of the National Institutes of Health under Award Number \#7K07CA184145-02. The content is solely the responsibility of the authors and does not necessarily represent the official views of the National Institutes of Health. We thank the study staff and all the transplant survivors who participated in this study for their time and dedication.

\section{References}

1. Gyurkocza B, Sandmaier BM. Conditioning regimens for hematopoietic cell transplantation: One size does not fit all. Blood. 2014; 124:344-353. [PubMed: 24914142]

2. McQuellon, RP.; Andrykowski, M. Thomas' Hematopoietic Cell Transplantation: Stem Cell Transplantation. 4th. 2009. Psychosocial issues in hematopoietic cell transplantation; p. 488-501.

3. Copelan EA. Hematopoietic stem-cell transplantation. N Engl J Med. 2006; 354:1813-1826. [PubMed: 16641398]

4. Austin, J.; Rini, C. Bone marrow stem cell transplant. In: Block, AR.; Sarwer, DB., editors. Presurgical Psychological Screening: Understanding Patients, Improving Outcomes. Washington, DC: American Psychological Association; 2013. p. 103-125.

5. Hamadani M, Craig M, Awan F, Devine S. How we approach patient evaluation for hematopoietic stem cell transplantation. Bone Marrow Transplant. 2010; 45:1259-1268. [PubMed: 20479713]

6. Braamse AMJ, Gerrits MMJG, van Meijel B, et al. Predictors of health-related quality of life in patients treated with auto- and allo-SCT for hematological malignancies. Bone Marrow Transplant. 2011; 47:757-769. [PubMed: 21725373]

7. Rodrigue JR, Pearman TP, Moreb J. Morbidity and mortality following bone marrow transplantation: Predictive utility of pre-BMT affective functioning, compliance, and social support stability. Int J Behav Med. 1999; 6:241-254. [PubMed: 16250678]

8. Kettmann JDJ, Altmaier EM. Social support and depression among bone marrow transplant patients. J Health Psychol. 2008; 13:39-46. [PubMed: 18086716]

9. Syrjala KL, Langer SL, Abrams JR, et al. Recovery and long-term function after hematopoietic cell transplantation for leukemia or lymphoma. JAMA. 2004; 291:2335-2343. [PubMed: 15150205]

10. Tolsdorf CC. Social networks, support, and coping: An exploratory study. Fam Process. 1976; 15:407-417. [PubMed: 1026458]

11. Vaux A, Burda P, Stewart D. Orientation toward utilization of support resources. J Community Psychol. 1986; 14:159-170.

12. Cohen S, Wills TA. Stress, social support, and the buffering hypothesis. Psychol Bull. 1985; 98:310. [PubMed: 3901065]

13. Cohen S, Doyle WJ, Skoner DP, Rabin BS, Gwaltney JM. Social ties and susceptibility to the common cold. JAMA. 1997; 277:1940-1944. [PubMed: 9200634]

14. Gottlieb BH, Bergen AE. Social support concepts and measures. J Psychosom Res. 2010; 69:511520. [PubMed: 20955871]

15. Mitchell PH, Powell L, Blumenthal J, et al. A short social support measure for patients recovering from myocardial infarction: the ENRICHD social support inventory. J Cardiopulm Rehabil Prev. 2003; 23:398-403.

16. Newsom JT, Rook KS, Nishishiba M, Sorkin DH, Mahan TL. Understanding the relative importance of positive and negative social exchanges: Examining specific domains and appraisals. J Gerontol B Psychol Sci Social Sci. 2005; 60:P304-P312.

17. Pinquart M, Duberstein PR. Associations of social networks with cancer mortality: A metaanalysis. Crit Rev Oncol Hematol. 2010; 75:122-137. [PubMed: 19604706]

18. Sapp AL, Trentham-Dietz A, Newcomb PA, et al. Social networks and quality of life among female long-term colorectal cancer survivors. Cancer. 2003; 98:1749-1758. [PubMed: 14534893]

19. Soares A, Biasoli I, Scheliga A, et al. Association of social network and social support with healthrelated quality of life and fatigue in long-term survivors of Hodgkin lymphoma. Support Care Cancer. 2013; 21:2153-2159. [PubMed: 23475196] 
20. Cohen S. Social relationships and health. Am Psychol. 2004; 59:676. [PubMed: 15554821]

21. Berkman LF, Glass T, Brissette I, Seeman TE. From social integration to health: Durkheim in the new millennium. Soc Sci Med. 2000; 51:843-857. [PubMed: 10972429]

22. Taylor SE. Social support. Foundations of health psychology. 2007:145-171.

23. Thoits PA. Mechanisms linking social ties and support to physical and mental health. J Health Soc Behav. 2011; 52:145-161. [PubMed: 21673143]

24. Newsom JT. Another side to caregiving: Negative reactions to being helped. Curr Dir Psychol Sci. 1999; 8:183-187.

25. Rook KS. The negative side of social-interaction: Impact on psychological well-being. J Pers Soc Psychol. 1984; 46:1097-1108. [PubMed: 6737206]

26. Rini C, Redd WH, Austin J, et al. Effectiveness of partner social support predicts enduring psychological distress after hematopoietic stem cell transplantation. J Consult Clin Psychol. 2011; 79:64. [PubMed: 21261435]

27. Rini, C.; Dunkel Schetter, C. The effectiveness of social support transactions in intimate relationships. In: Sullivan, KT.; Davila, J., editors. Support Processes in Intimate Relationships. New York: Oxford University Press; 2010. p. 26-67.

28. Haber MG, Cohen JL, Lucas T, Baltes BB. The relationship between self-reported received and perceived social support: A meta-analytic review. Am J Community Psychol. 2007; 39:133-144. [PubMed: 17308966]

29. Uchino BN. Understanding the links between social support and physical health: A life-span perspective with emphasis on the separability of perceived and received support. Perspect Psychol Sci. 2009; 4:236-255. [PubMed: 26158961]

30. Dunkel-Schetter, C.; Bennett, TL. Differentiating the cognitive and behavioral aspects of social support. In: Sarason, BR.; Sarason, IG.; Pierce, GR., editors. Social Support: An Interactional View. New York: John Wiley \& Sons; 1990. p. 267-296.

31. Norris FH, Kaniasty K. Received and perceived social support in times of stress: A test of the social support deterioration deterrence model. J Pers Soc Psychol. 1996; 71:498-511. [PubMed: 8831159]

32. Thoits PA. Multiple identities and psychological well-being-A reformulation and test of the social-isolation hypothesis. Am Sociol Rev. 1983; 48:174-187. [PubMed: 6859677]

33. Brissette, I.; Cohen, S.; Seeman, TE. Measuring social integration and social networks. In: Cohen, S.; Underwood, LG.; Gottlieb, BH., editors. Social Support Measurement and Intervention. New York: Oxford University Press; 2000. p. 53-85.

34. Vaux A. Factor structure of the network orientation scale. Psychol Rep. 1985; 57:1181-1182.

35. Eckenrode J. The mobilization of social supports: Some individual constraints. Am J Community Psychol. 1983; 11:509-528. [PubMed: 6650459]

36. Hobfoll SE, Lerman M. Predicting receipt of social support: A longitudinal study of parents' reactions to their child's illness. Health Psychol. 1989; 8:61. [PubMed: 2707224]

37. Kaniasty K, Norris FH. Help-seeking comfort and receiving social support: The role of ethnicity and context of need. Am J Community Psychol. 2000; 28:545-581. [PubMed: 10965390]

38. Nadler, A. Sourcebook of social support and personality. Springer; 1997. Personality and help seeking; p. 379-407.

39. Rini C, Schetter CD, Hobel CJ, Glynn LM. Sandman CA Effective social support: Antecedents and consequences of partner support during pregnancy. Pers Relatsh. 2006; 13:207-229.

40. Rini C, Austin J, Wu LM, et al. Harnessing benefits of helping others: A randomized controlled trial testing expressive helping to address survivorship problems after hematopoietic stem cell transplant. Health Psychol. 2014; 33:1541-1551. [PubMed: 24274798]

41. Derogatis, LR.; Spencer, P. Brief Symptom Inventory: BSI. NJ: Pearson Upper Saddle River; 1993.

42. Horowitz M, Wilner N, Alvarez W. Impact of event scale: A measure of subjective stress. Psychosom Med. 1979; 41:209-218. [PubMed: 472086]

43. McQuellon R, Russell G, Cella D, et al. Quality of life measurement in bone marrow transplantation: Development of the functional assessment of cancer therapy-bone marrow transplant (FACT-BMT) scale. Bone Marrow Transplant. 1997; 19:357-368. [PubMed: 9051246] 
44. Cella, D. Manual of the Functional Assessment of Chronic Illness Therapy (FACIT) Measurement System, Version 4. Evanston: Center on Outcomes, Research and Education (CORE), Evanston Northwestern Healthcare and Northwestern University; 1997.

45. Scheier MF, Wrosch C, Baum A, et al. The life engagement test: Assessing purpose in life. J Behav Med. 2006; 29:291-298. [PubMed: 16565785]

46. Leger CS, Nevill TJ. Hematopoietic stem cell transplantation: A primer for the primary care physician. CMAJ. 2004; 170:1569-1577. [PubMed: 15136552]

47. Sangha O, Stucki G, Liang MH, Fossel AH, Katz JN. The self- administered comorbidity questionnaire: A new method to assess comorbidity for clinical and health services research. Arthritis Care Res. 2003; 49:156-163.

48. Bentler, P. EQS 6 Structural Equations Program Manual. Encino: Multivariate Software, Inc; 2008.

49. Browne, MW.; Cudeck, R. Alternative ways of assessing model fit. In: Bollen, KA.; Long, JS., editors. Testing Structural Equation Models. Newbury Park: Sage; 1993. p. 136-162.

50. Hu LT, Bentler PM. Cutoff criteria for fit indexes in covariance structure analysis: Conventional criteria versus new alternatives. Struct Equ Modeling. 1999; 6:1-55.

51. Wallace JL, Vaux A. Social support network orientation: The role of adult attachment style. J Soc Clin Psychol. 1993; 12:354-365.

52. Clapp JD, Gayle Beck J. Understanding the relationship between PTSD and social support: The role of negative network orientation. Behav Res Ther. 2009; 47:237-244. [PubMed: 19162260]

53. Pidala J, Kurland B, Chai X, et al. Patient-reported quality of life is associated with severity of chronic graft-versus-host disease as measured by NIH criteria: Report on baseline data from the Chronic GVHD Consortium. Blood. 2011; 117:4651-4657. [PubMed: 21355084]

54. O'Mara-Eves A, Brunton G, Oliver S, et al. The effectiveness of community engagement in public health interventions for disadvantaged groups: A meta-analysis. BMC Public Health. 2015; 15:129. [PubMed: 25885588]

55. Anders SL, Tucker JS. Adult attachment style, interpersonal communication competence, and social support. Pers Relatsh. 2000; 7:379-389.

56. Hazan C, Shaver P. Romantic love conceptualized as an attachment process. J Pers Soc Psychol. 1987; 52:511-524. [PubMed: 3572722]

57. Collins NL, Feeney BC. Working models of attachment shape perceptions of social support: Evidence from experimental and observational studies. J Pers Soc Psychol. 2004; 87:363-383. [PubMed: 15382986]

58. Selig JP, Preacher KJ. Mediation models for longitudinal data in developmental research. Res Hum Dev. 2009; 6:144-164.

59. Uchino, BN. Social Support and Physical Health: Understanding the Health Consequences of Relationships. New Haven: Yale University Press; 2004.

60. Holt-Lunstad J, Smith TB, Layton JB. Social relationships and mortality risk: A meta-analytic review. PLoS Med. 2010; 7:e1000316.. [PubMed: 20668659]

61. Preacher KJ. Advances in mediation analysis: A survey and synthesis of new developments. Annu Rev Psychol. 2015; 66:825-852. [PubMed: 25148853]

62. Joshua TV, Rizzo JD, Zhang M-J, et al. Access to hematopoietic stem cell transplantation. Cancer. 2010; 116:3469-3476. [PubMed: 20564154] 


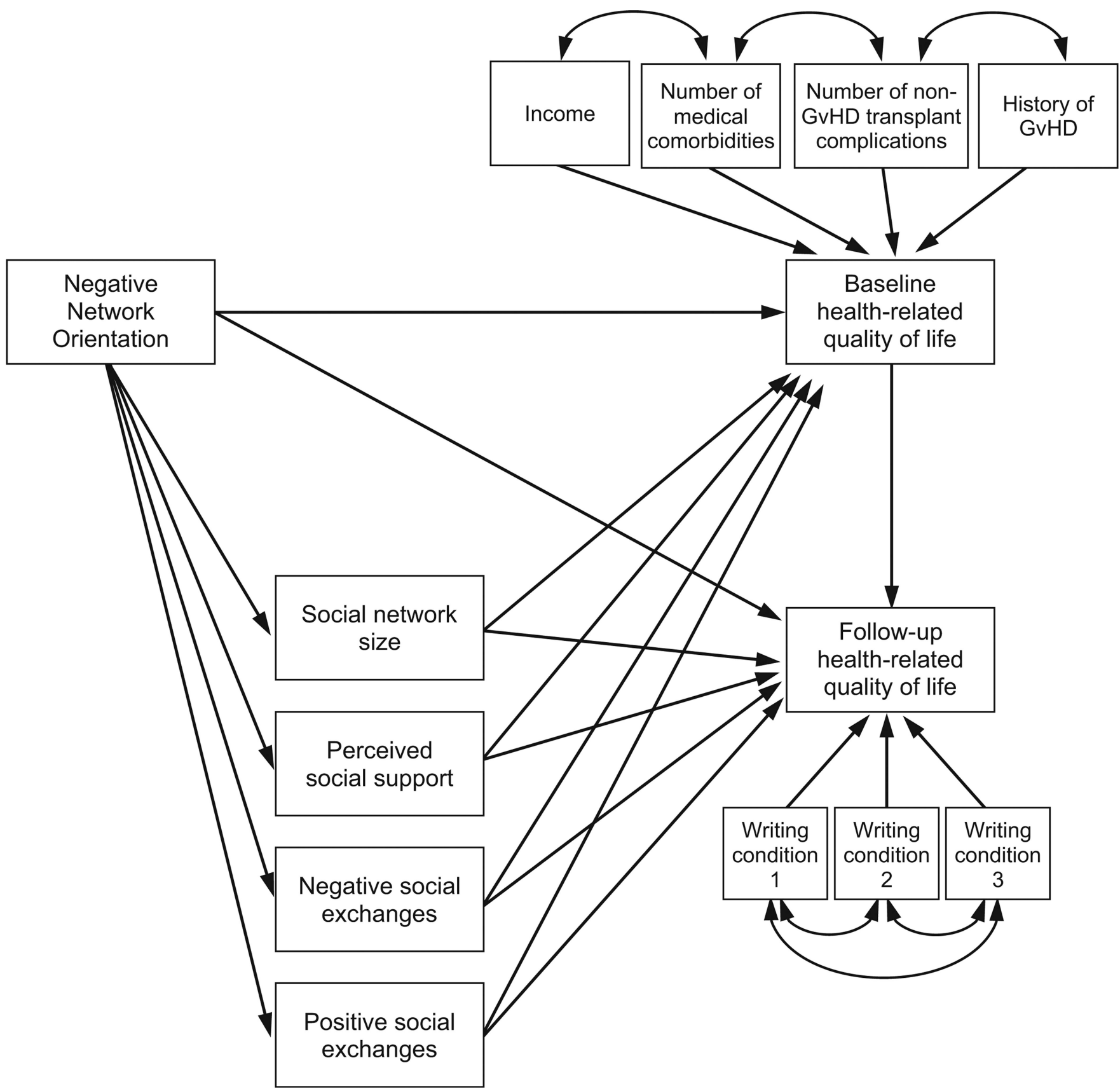

Fig. 1.

Hypothesized model of relations among negative social network orientation, social resources, and health-related quality of life among cancer survivors treated with hematopoietic stem cell transplant. Error terms are omitted for clarity. GVHD graft versus host disease 


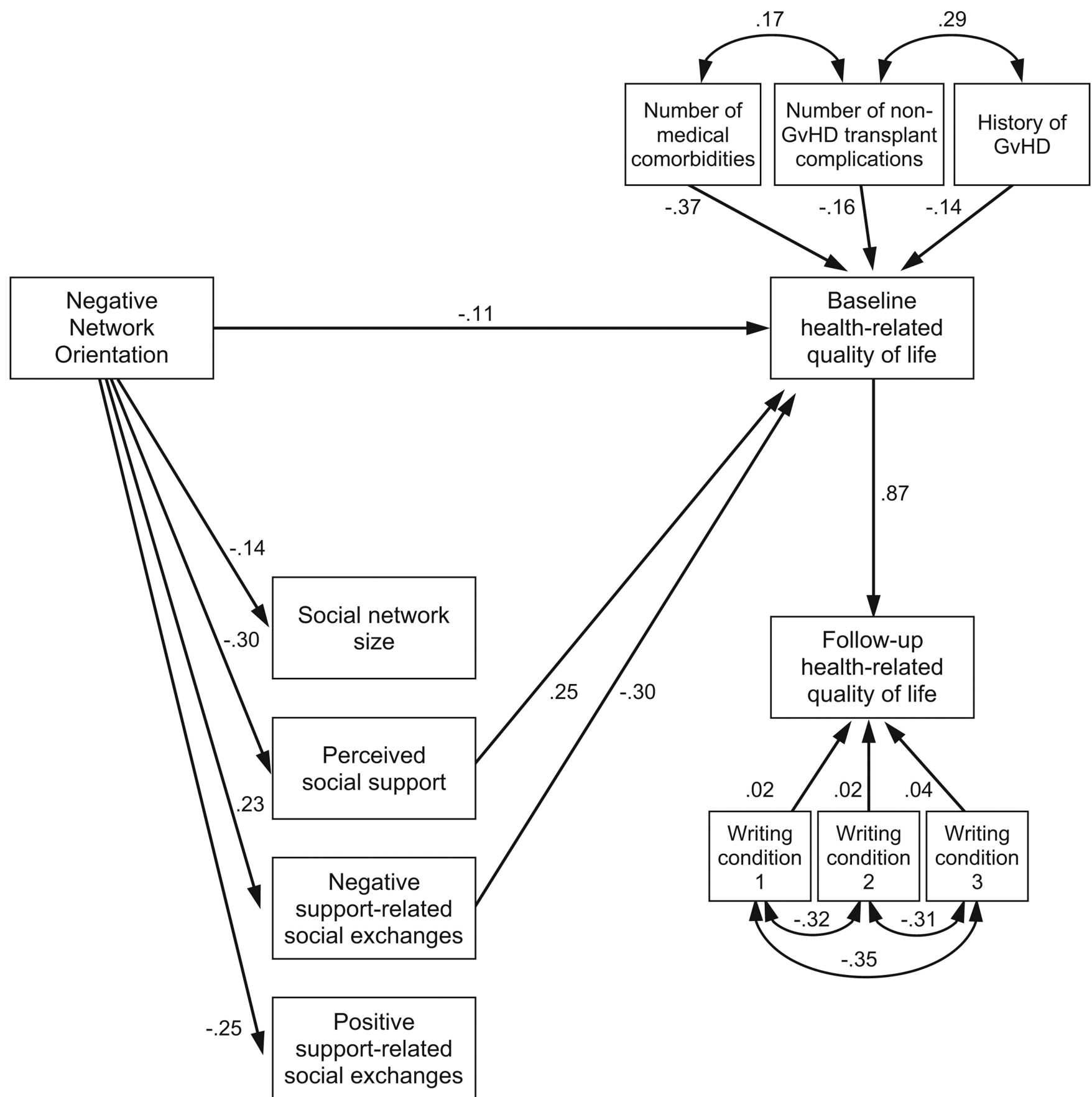

Fig. 2.

Final model of relations among social network orientation, social resources, and healthrelated quality of life among cancer survivors treated with hematopoietic stem cell transplant. Standardized estimates are shown. Error terms are omitted for clarity. All estimates are significant at the $p<.05$ level except for estimates for the direct paths between writing conditions 1, 2, and 3 and follow-up health-related quality of life. $G V H D$ graft versus host disease 


\section{Table 1}

Participant characteristics $(N=255)$

\begin{tabular}{|c|c|c|c|}
\hline & Number (\%) & $M(\mathbf{S D})$ & Observed range \\
\hline Female & $147(58 \%)$ & & \\
\hline Age (in years) & & $54(12)$ & $19-79$ \\
\hline \multicolumn{4}{|l|}{ Race/ethnicity } \\
\hline Non-Hispanic white & $219(86 \%)$ & & \\
\hline Black/African-American & $10(4 \%)$ & & \\
\hline Hispanic/Latino(a) & $10(4 \%)$ & & \\
\hline Asian/Pacific Islander & $6(2 \%)$ & & \\
\hline Others & $10(4 \%)$ & & \\
\hline \multicolumn{4}{|l|}{ Marital status } \\
\hline Married/marriage-like relationship & $189(74 \%)$ & & \\
\hline Single/never married & $31(12 \%)$ & & \\
\hline Divorced or separated & $26(10 \%)$ & & \\
\hline Widowed & $9(4 \%)$ & & \\
\hline \multicolumn{4}{|l|}{ Education } \\
\hline High school graduate & $30(12 \%)$ & & \\
\hline Some college/trade school & $54(21 \%)$ & & \\
\hline Four-year college degree & $90(35 \%)$ & & \\
\hline Graduate degree & $80(31 \%)$ & & \\
\hline Missing & $1(<1 \%)$ & & \\
\hline Annual household income (median) & & $\$ 80,000-95,000$ & $<\$ 20,000->110,000$ \\
\hline Autologous & $140(55 \%)$ & & \\
\hline Allogeneic & $115(45 \%)$ & & \\
\hline \multicolumn{4}{|l|}{ Diagnosis } \\
\hline Lymphoma & $82(32 \%)$ & & \\
\hline Multiple myeloma & $77(30 \%)$ & & \\
\hline Leukemia & $58(23 \%)$ & & \\
\hline Others & $38(15 \%)$ & & \\
\hline History of graft versus host disease (GvHD) & & $94(37 \%)$ & \\
\hline Number of non-GvHD transplant complications & & $2.61(1.70)$ & $0-8$ \\
\hline Number of medical comorbidities & & $1.22(1.22)$ & $0-6$ \\
\hline Baseline health-related quality of life & & $112.07(18.70)$ & $59-146$ \\
\hline Follow-up health-related quality of life & & $113.37(19.49)$ & $53-154.34$ \\
\hline Social network orientation & & $37.24(5.51)$ & $21-52$ \\
\hline Perceived social support & & $29.07(4.14)$ & $13-35$ \\
\hline Social network size & & $19.26(11.76)$ & $2-77$ \\
\hline Positive support-related social exchanges & & $45.07(6.79)$ & $26-60$ \\
\hline Negative support-related social exchanges & & $21.62(6.23)$ & $12-48$ \\
\hline
\end{tabular}

Ann Behav Med. Author manuscript; available in PMC 2016 June 01. 


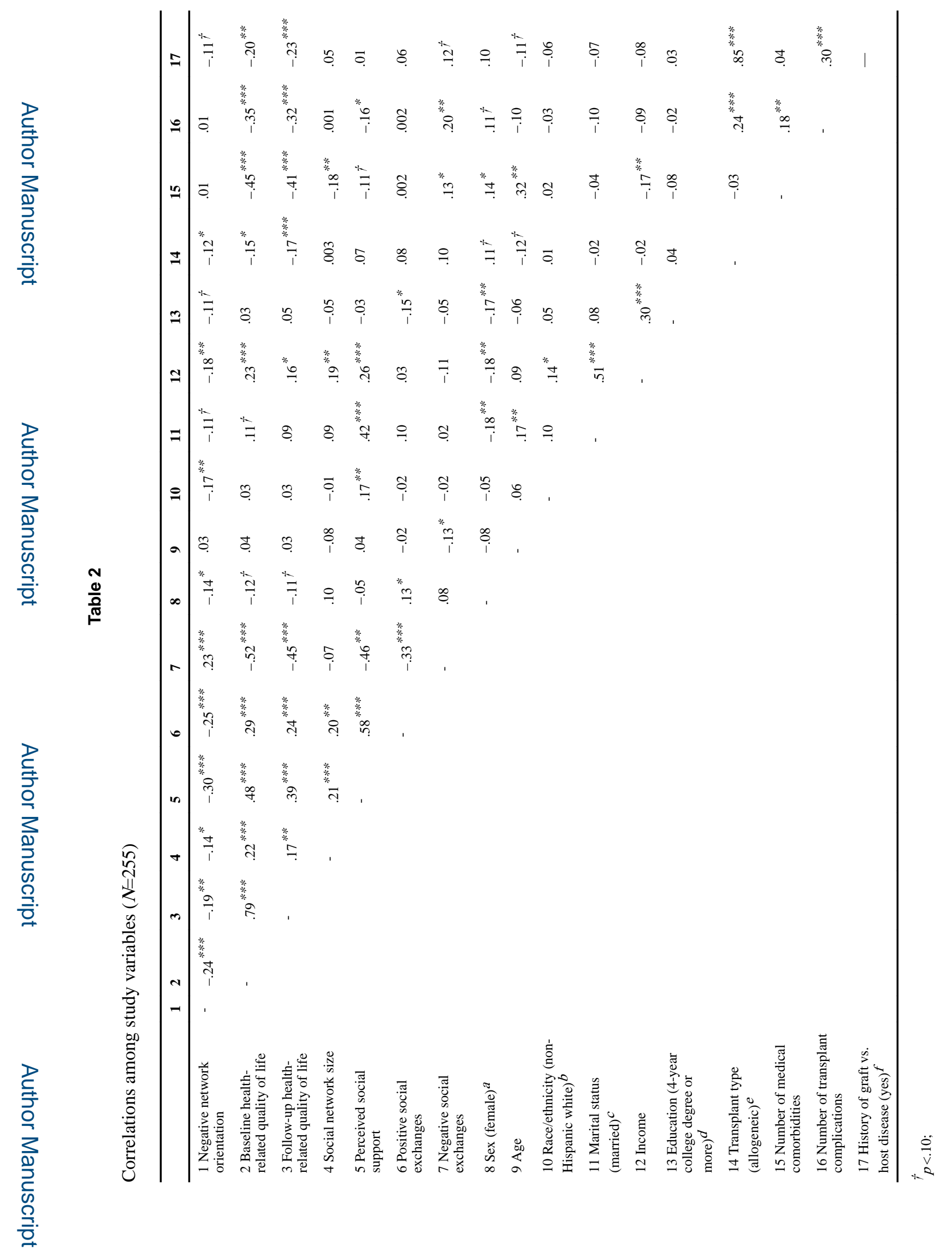

Ann Behav Med. Author manuscript; available in PMC 2016 June 01. 

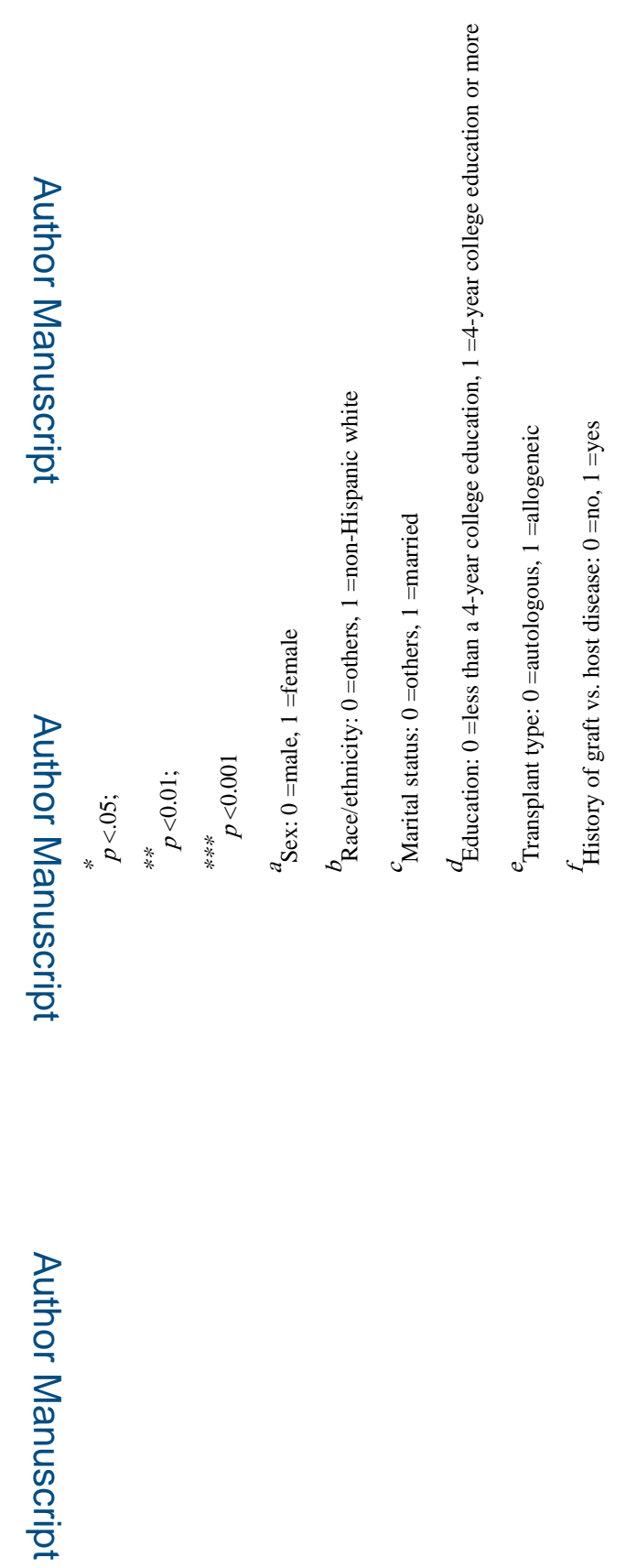

를

Ann Behav Med. Author manuscript; available in PMC 2016 June 01. 